\title{
Article \\ Umbelliferone Ameliorates Benign Prostatic Hyperplasia by Inhibiting Cell Proliferation and G1/S Phase Cell Cycle Progression through Regulation of STAT3/E2F1 Axis
}

\author{
Hyo-Jung Kim, Bo-Ram Jin and Hyo-Jin An *(D) \\ Department of Pharmacology, College of Korean Medicine, Sang-ji University, Wonju-si 26339, Korea; \\ hyojung_95@naver.com (H.-J.K.); wlsqh92@gmail.com (B.-R.J.) \\ * Correspondence: sangjipharm@gmail.com; Tel.: +82-33-738-7503; Fax: +82-33-730-0679
}

\section{check for}

updates

Citation: Kim, H.-J.; Jin, B.-R.; An, H.-J. Umbelliferone Ameliorates Benign Prostatic Hyperplasia by Inhibiting Cell Proliferation and G1/S Phase Cell Cycle Progression through Regulation of STAT3/E2F1 Axis. Int. J. Mol. Sci. 2021, 22, 9019. https:// doi.org/10.3390/ijms22169019

Academic Editors: Jong Kwan Park Keshab Kumar Karna and Yu Seob Shin

Received: 30 July 2021

Accepted: 19 August 2021

Published: 21 August 2021

Publisher's Note: MDPI stays neutral with regard to jurisdictional claims in published maps and institutional affiliations.

Copyright: (c) 2021 by the authors. Licensee MDPI, Basel, Switzerland. This article is an open access article distributed under the terms and conditions of the Creative Commons Attribution (CC BY) license (https:/ / creativecommons.org/licenses/by/ $4.0 /)$.

\begin{abstract}
Umbelliferone (UMB), also known as 7-hydroxycoumarin, is a derivative of coumarin, which is widely found in many plants such as carrots, coriander, and garden angelica. Although many studies have already revealed the various pharmacological properties of UMB, its effect on benign prostatic hyperplasia $(\mathrm{BPH})$ remains unclear. Therefore, the present study aimed to elucidate the underlying mechanism of the anti-proliferative effect of UMB in a human benign prostatic hyperplasia cell line (BPH-1), as well as its ameliorative effect on BPH in testosterone propionate (TP)-induced rats. The results showed that UMB exerts an anti-proliferative effect in BPH-1 cells by modulating the signal transducer and activator of transcription 3 (STAT3)/E2F transcription factor 1 (E2F1) axis. UMB treatment not only inhibited androgen/androgen receptor (AR) signaling-related markers, but also downregulated the overexpression of G1/S phase cell cycle-related markers. In TP-induced rats, UMB administration demonstrated an anti-BPH effect by significantly reducing prostate size, weight, and epithelial thickness. In addition, UMB suppressed cell proliferation by reducing the expression of proliferating cell nuclear antigen (PCNA) and p-STAT3 (Tyr 705) in prostate tissue following TP injection. These findings suggest that UMB has pharmacological effects against $\mathrm{BPH}$.
\end{abstract}

Keywords: androgen receptor; benign prostatic hyperplasia; E2F transcription factor 1; signal transducer and activator of transcription 3; testosterone propionate; umbelliferone

\section{Introduction}

Benign prostatic hyperplasia (BPH), a common disorder that occurs in older men, is characterized by uncontrolled proliferation of the prostate, an encapsulated accessory reproductive gland surrounding the bladder neck and proximal urethra [1]. An enlarged prostate gradually compresses the urethra, resulting in lower urinary tract symptoms (LUTS), such as a weak stream, residual urine, urinary frequency, urgency, and nocturia; consequently, it negatively impacts the quality of life of the patient [2]. Although various risk factors, including hormonal changes, aging, and growth factors, have been hypothesized to be associated with the onset and progression of $\mathrm{BPH}$, a consensus on the etiology of BPH has not yet been reached [3].

Dihydrotestosterone (DHT), a form of circulating testosterone converted by $5 \alpha$ reductase (5AR) presents in the prostate, plays an important role in the development of BPH [4]. Finasteride (Fina), a 5AR-inhibitor (5ARI) that is used to treat symptomatic $\mathrm{BPH}$ by preventing the conversion of testosterone to DHT, relieves dysuria by reducing the size of the enlarged prostate [5]. Unfortunately, numerous clinical studies have reported that 5ARI therapy causes adverse effects such as decreased libido, impaired ejaculation, and erectile dysfunction [6]. For this reason, the need for natural medicines to replace existing synthetic drugs is emerging [7]. Saw palmetto (Saw), an extract from the fruit of the American dwarf palm tree, Serenoa repens, is a relatively stable botanical agent used 
against the side effects of chemotherapy [8]. It is widely used in the treatment of LUTS and acts by inhibiting $5 \mathrm{AR}$ via a mechanism similar to that of Fina, but does not effectively reduce prostate size [9]. Therefore, there is a pressing need to identify alternative agents with reduced side effects that are capable of exerting the anti-BPH effect and determine their molecular mechanisms. Androgen receptor (AR), a member of the nuclear receptor superfamily, is a ligand-responsive transcription factor that mediates signaling by androgens, including DHT [10]. The transcriptional activation of AR triggers the transcription of target genes responsible for cell proliferation, along with co-regulators such as the steroid receptor coactivator (SRC) family, SRC-1 [11]. Therefore, targeting the androgen/AR signaling pathway is a major therapeutic approach against BPH.

Unregulated cell proliferation and reduction of apoptosis cause an increase in the total number of prostate cells during progression of BPH [12]. The division and replication of prostate cells are governed by the cell cycle consisting of four phases, among which failure of the G1/S checkpoint causes uncontrolled DNA replication, leading to aberrant cell proliferation [13]. The transition from $\mathrm{G} 1$ to $S$ phase is primarily regulated by the cyclincyclin-dependent kinase (Cdk) complex that phosphorylates retinoblastoma $(\mathrm{Rb})$, with the liberation of E2F transcription factors [14]. Signal transducer and transcription activator 3 (STAT3) is a member of the STAT family and is expressed in most tissue types. It is a latent cytoplasmic transcription factor that has a dual molecular role as a signal transducer and transcriptional activator [15]. Upon tyrosine phosphorylation by stimuli such as cytokines or growth factors, STAT3 is translocated into the nucleus where it regulates the transcription of target genes, thereby participating in several cellular processes, including cell proliferation and differentiation [16].

Umbelliferone (UMB) is a synthetic form of coumarin, a natural phenolic constituent widely distributed in the Rutaceae and Apiaceae (Umbelliferae) families [17]. UMB, which has excellent nutritional value, is commonly found in numerous fruits, vegetables, and plants (e.g., carrots, coriander, garden angelica) [18]. In previous studies, UMB has been reported to have antioxidant, anti-inflammatory, and anti-tumor effects [19-21]. Owing to its wide range of pharmacological and biological activities, UMB has drawn considerable attention as an attractive phytochemical in the fields of nutritional supplements, functional foods, and pharmaceuticals. Recently, the anti-carcinogenic effect of UMB was demonstrated in the prostate, but its effect on BPH has not yet been elucidated [22]. Hence, this study aimed to evaluate the potential of UMB as a therapeutic agent for BPH by identifying the effect of UMB on dysregulated cell proliferation and G1/S phase cell cycle progression in BPH-1 cells and TP-induced rats.

\section{Results}

\subsection{Effect of UMB on the Blockade of Androgen/AR Signaling in BPH-1 Cells}

To evaluate the inhibitory effect of UMB on cell proliferation, an MTT assay was performed using BPH-1 cells derived from the prostate epithelium of an older man with $\mathrm{BPH}$. BPH-1 cells were treated with various concentrations $(6.25-400 \mu \mathrm{M})$ of UMB for $24 \mathrm{~h}$. The growth of BPH-1 cells was significantly hampered by UMB concentrations above $200 \mu \mathrm{M}$ (Figure 1B). In addition, to validate the anti-proliferative effect of UMB, the expression of proliferating cell nuclear antigen (PCNA) was confirmed through Western blot analysis. Treatment with $\operatorname{UMB}(100,200$, and $400 \mu \mathrm{M})$ reduced PCNA protein expression in a concentration-dependent manner (Figure 1C). Activated AR signaling has a causative role in $\mathrm{BPH}$ progression by inducing the production of androgen-regulated genes, such as PSA, and promoting prostate growth [23]. To examine whether UMB interferes with androgen/AR signaling, the expression of androgen-related genes was detected. Protein expression of AR, SRC-1, and PSA, which was elevated in BPH-1 cells, was reduced following UMB treatment (Figure 1D). Similar to the results of Western blot analysis, UMB treatment of BPH-1 cells markedly downregulated the mRNA expression of PCNA, AR, SRC-1, and PSA (Figure 1E). 
<smiles>O=c1ccc2ccc(O)cc2o1</smiles>
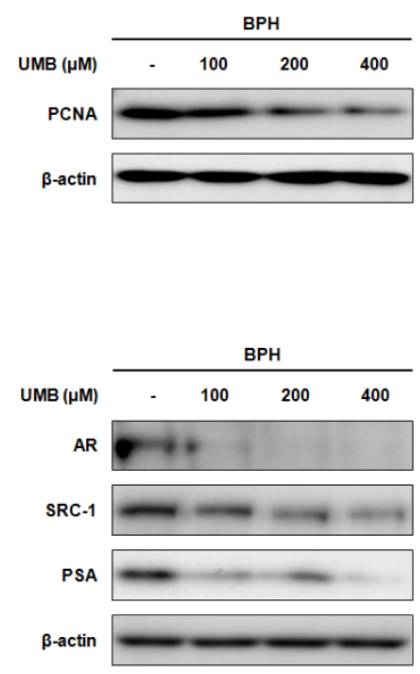
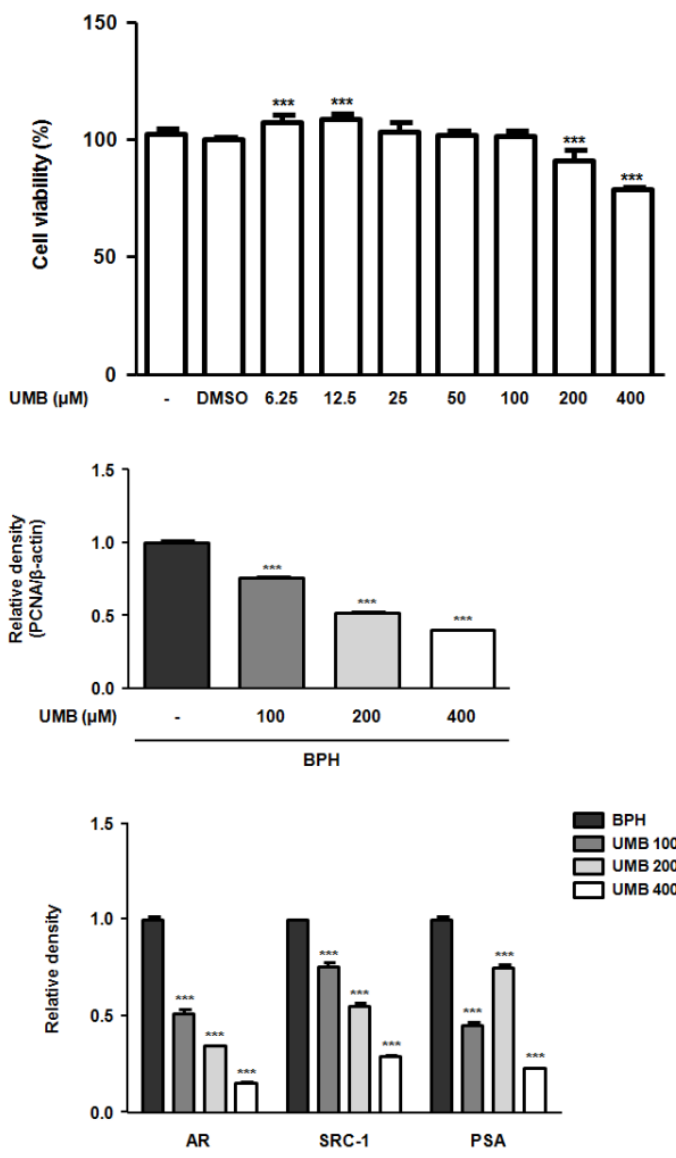

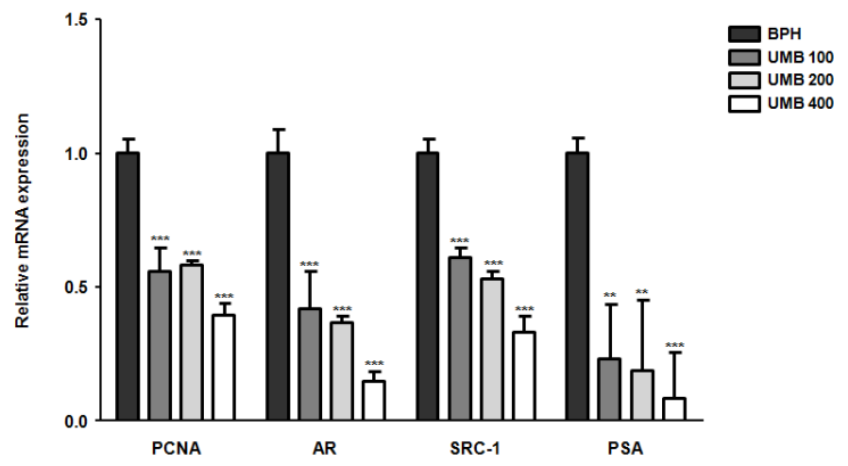

Figure 1. Effect of UMB on the blockade of androgen/AR signaling in BPH-1 cells. (A) Molecular structure of UMB. (B) BPH-1 cells were treated with or without different concentrations (6.25-400 $\mu \mathrm{M})$ of UMB for $24 \mathrm{~h}$, and cell viability was assessed. (C,D) BPH-1 cells were treated with or without 100, 200, and $400 \mu \mathrm{M}$ of UMB. The protein expression of (C) PCNA, (D) AR, SRC-1, and PSA was determined by Western blot analysis using specific antibodies. The relative density of the proteins was normalized to that of $\beta$-actin, which was used as an internal control. (E) The mRNA expression of PCNA, AR, SRC-1, and PSA was quantified using qRT-PCR in BPH-1 cells. The relative mRNA expression was normalized using the $\mathrm{Ct}$ value of $\beta$-actin. The values represent as mean \pm standard deviation (S.D.) of three independent experiments. ${ }^{* *} p<0.01,{ }^{* * *} p<0.001$ vs. vehicle control.

\subsection{Effect of UMB on G1/S Phase Cell Cycle Arrest in BPH-1 Cells}

Progression of the cell cycle, comprising G1, S, G2, and M phases, is known to play a pivotal role in cellular responses, including cell proliferation [24]. Controlling the first 
checkpoint, the G1/S phase, is an essential step in cell cycle regulation, as cells are generally committed to the division following DNA replication [25]. Thus, we investigated the effect of UMB on the expression of the cyclin-Cdk complex that regulates the G1/S phase. In BPH-1 cells, overexpression of cyclin D1-Cdk4 and cyclin E-Cdk2 proteins was decreased

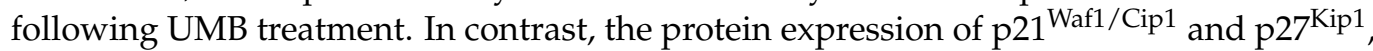
Cdk inhibitors, was increased by UMB treatment (Figure 2A). The qRT-PCR results showed that UMB treatment also suppressed the mRNA expression of cyclin D1-Cdk4 and cyclin E-Cdk2 while increasing the mRNA expression of p27 ${ }^{\text {Kip } 1 ~(F i g u r e ~ 2 B) . ~ T h e ~ t r a n s c r i p t i o n ~}$ factor E2F1 and tumor suppressor protein $\mathrm{Rb}$, the two major regulators of cell cycle progression, play a role in determining progression through the G1/S phase [26]. High expression of $\mathrm{Rb}$ phosphorylation $(\mathrm{pRb})$ and $\mathrm{E} 2 \mathrm{~F} 1$ protein in $\mathrm{BPH}-1$ cells, characterized by abnormal proliferation, was reversed by UMB treatment (Figure 2C). Likewise, the mRNA expression of $\mathrm{Rb}$ was upregulated, and that of $\mathrm{E} 2 \mathrm{~F} 1$ was downregulated by $\mathrm{UMB}$ treatment (Figure 2D).

A

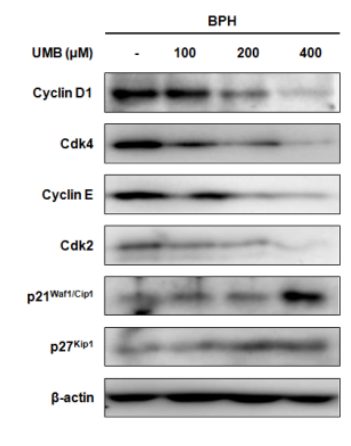

c

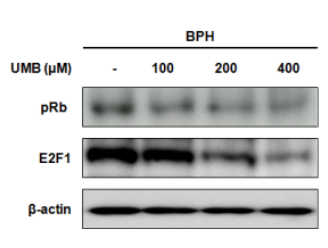

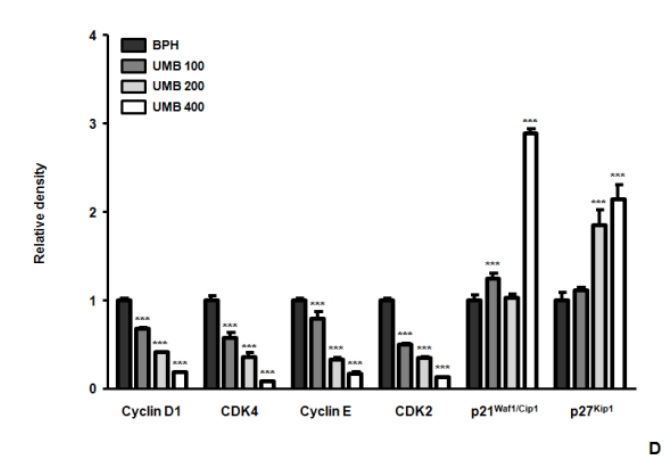

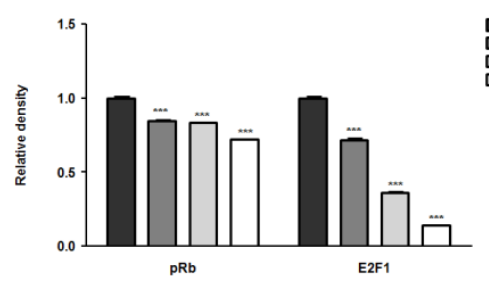

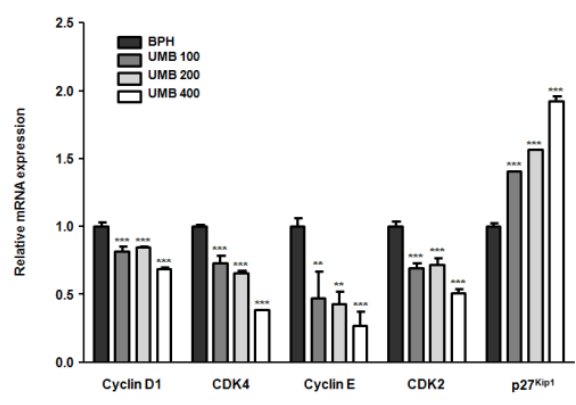

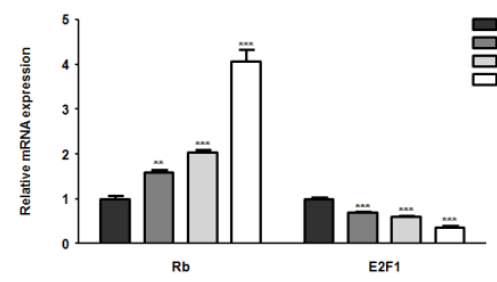

Figure 2. Effect of UMB on cell cycle arrest at the G1/S phase in BPH-1 cells. (A-D) BPH-1 cells were treated with or without 100, 200, and $400 \mu \mathrm{M}$ of UMB. The protein expression of (A) cyclin D1, Cdk4, cyclin E, Cdk2, p21 Waf1/Cip1 , p27Kip1, (C) pRb and E2F1 was determined by Western blot analysis using specific antibodies. The relative density of the protein was normalized to that of $\beta$-actin, which was used as an internal control. The mRNA expression of (B) cyclin D1, Cdk4, cyclin E, Cdk2, p27 Kip1, (D) Rb, and E2F1 was quantified using qRT-PCR in BPH-1 cells. The relative mRNA expression was normalized using the $\mathrm{Ct}$ value of $\beta$-actin. The values represent as mean \pm S.D. of three independent experiments. ${ }^{* *} p<0.01,{ }^{* * *} p<0.001$ vs. vehicle control.

\subsection{Effect of UMB Treatment on E2F1 Expression in BPH-1 Cells}

Overexpression of E2F1 triggers uncontrolled cell proliferation leading to various diseases, including tumors [26]. Immunofluorescence analysis was performed to confirm the effect of UMB on E2F1 expression in BPH-1 cells. BPH-1 cells were identified by nuclear staining with DAPI, and E2F1-positive cells were detected as green fluorescence by Alexa Fluor 488. The large number of E2F1-positive cells visualized in BPH-1 cells was significantly suppressed by UMB treatment (Figure 3). These data support the hypothesis that the inhibitory effect of UMB on E2F1 expression is associated with the regulation of cell proliferation. 


\section{$\mathrm{BPH}$}

UMB ( $\mu \mathrm{M})$
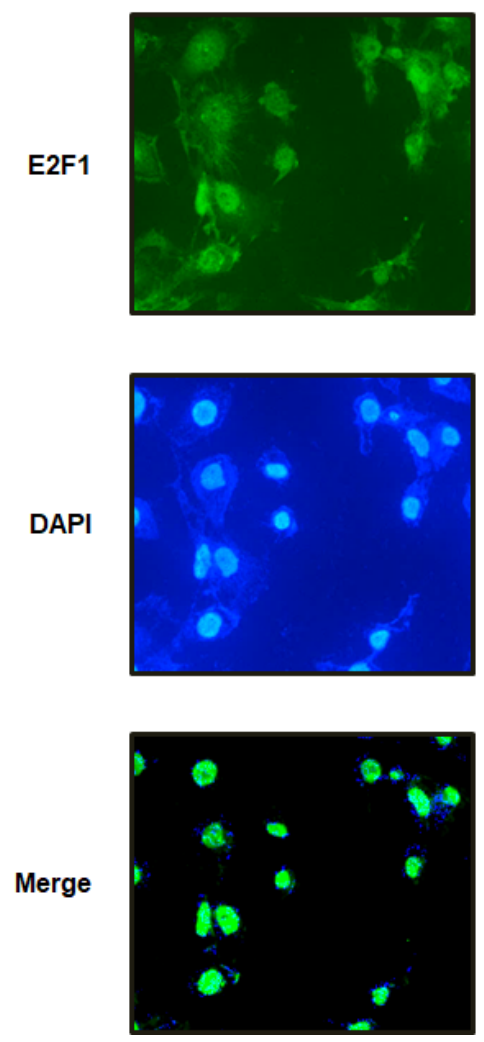

100
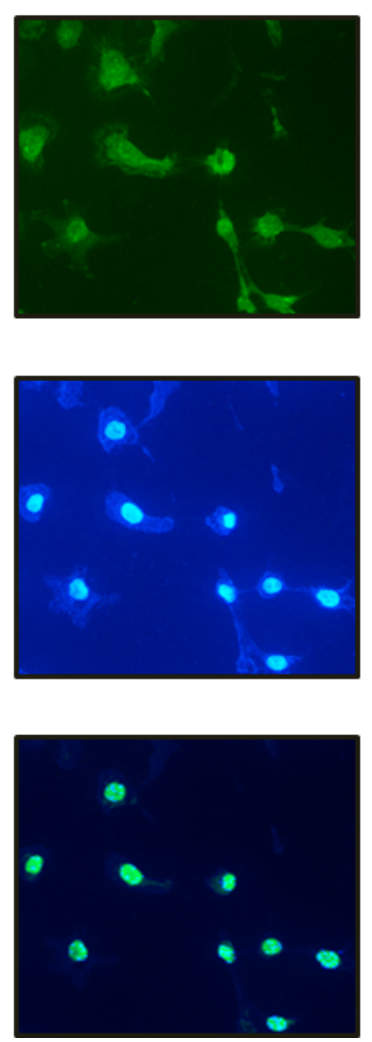

200
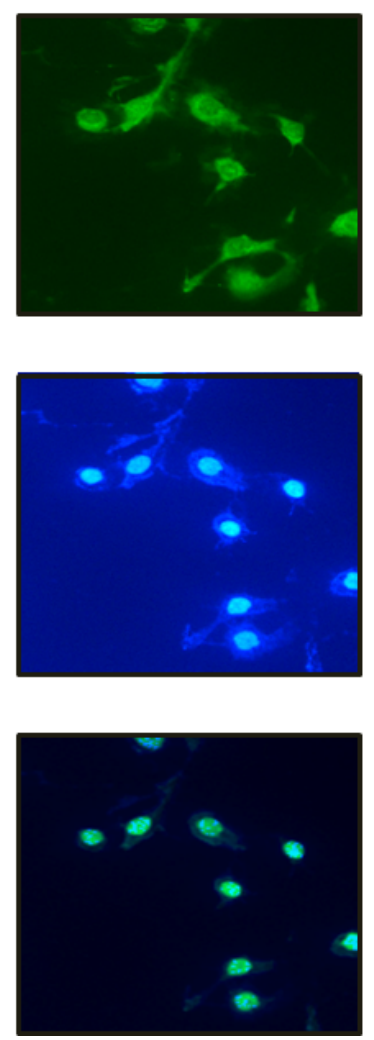

400
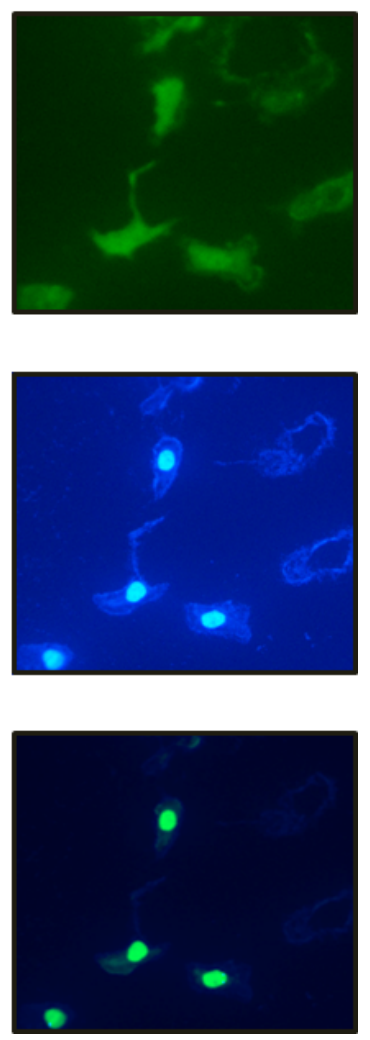

Figure 3. Effect of UMB treatment on E2F1 expression in BPH-1 cells. BPH-1 cells were treated with or without 100, 200, and $400 \mu \mathrm{M}$ of UMB. Alexa Fluor 488-incorporated cells (green) were detected by immunofluorescence staining for E2F1. The nuclei were counterstained with DAPI (blue). Merged images represent staining for E2F1 and DAPI. The stained cells were visualized with a fluorescence microscope at $400 \times$ magnification.

\subsection{Effect of UMB Treatment on TGF $\beta 1$ and p-STAT3 (Tyr 705) Expression in BPH-1 Cells}

Transforming growth factor beta 1 (TGF $\beta 1$ ) encodes a protein that regulates many biological processes, including cell proliferation, differentiation, and growth [27]. STAT3, a member of the family of latent transcription factors, is activated by cytokines and growth factors to transcriptionally regulate the expression of genes involved in proliferation and survival [28]. TGF $\beta 1$ also enhances the nuclear localization of p-STAT3 by activating the STAT3 signaling pathway. Therefore, Western blot analysis and qRT-PCR were performed to determine whether UMB treatment of BPH-1 cells inhibited cell proliferation by blocking TGF $\beta 1$ and STAT3 activation. The protein expression of TGF $\beta 1$ and p-STAT3 (Tyr 705), which showed high expression in BPH-1 cells, was suppressed following UMB treatment (Figure 4A). Similarly, the mRNA expression of TGF $\beta 1$ was also significantly reduced following UMB treatment (Figure 4B). Therefore, these data suggest that UMB inhibits the proliferation of BPH- 1 cells by impeding TGF $\beta 1$ and STAT3 activation. 
A
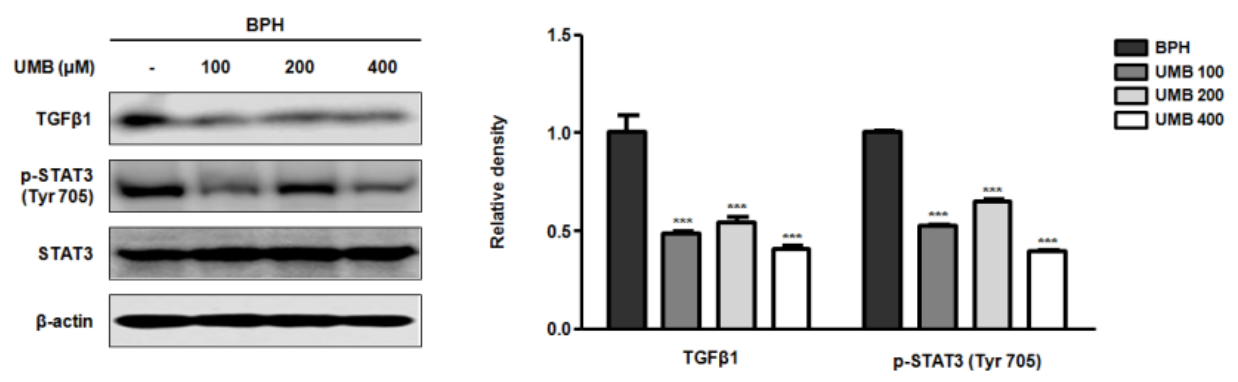

B

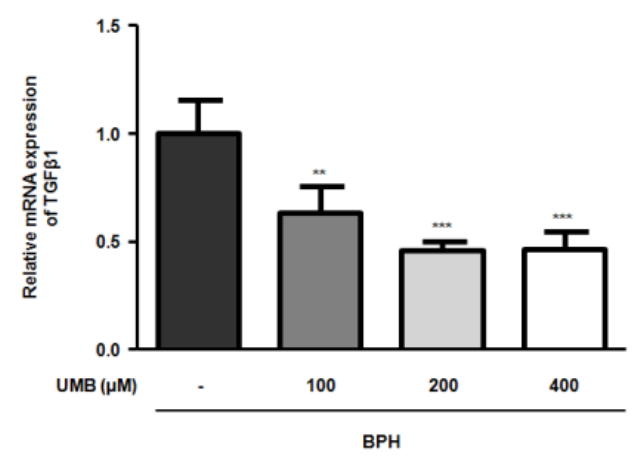

Figure 4. Effect of UMB treatment on TGF $\beta 1$ and p-STAT3 (Tyr 705) expression in BPH-1 cells. (A,B) BPH-1 cells were treated with or without 100, 200, and $400 \mu \mathrm{M}$ of UMB. (A) Protein expression of TGF $\beta 1$ and p-STAT3 (Tyr 705) was determined by Western blot analysis using specific antibodies. The relative protein density was normalized to that of $\beta$-actin, which was used as an internal control. (B) The mRNA expression of TGF $\beta 1$ was quantified using qRT-PCR in BPH-1 cells. The relative mRNA expression was normalized using the $\mathrm{Ct}$ value of $\beta$-actin. The values represent as mean \pm S.D. of three independent experiments. ${ }^{* *} p<0.01,{ }^{* * *} p<0.001$ vs. vehicle control.

\subsection{Effect of UMB on Prostate Enlargement in TP-Induced Rats}

Rats with BPH were established by pre-injecting TP for four weeks, following which Fina $(5 \mathrm{mg} / \mathrm{kg})$, Saw $(100 \mathrm{mg} / \mathrm{kg})$, and UMB (50 or $100 \mathrm{mg} / \mathrm{kg}$ ) were administered orally for four weeks (Figure 5A). To investigate the effect of UMB administration in vivo, the prostates were resected from the rats and analyzed. Visual comparison of prostate specimens from each group revealed that the prostate that had enlarged following TP following TP injection was reduced by administration of Fina, Saw, and UMB (50 or $100 \mathrm{mg} / \mathrm{kg}$ ) (Figure 5B). Prostate weight was markedly increased in the TP group compared to Con group, whereas it was significantly decreased by administration of Fina, Saw, and UMB (50 or $100 \mathrm{mg} / \mathrm{kg}$ ) (Figure 5C). Similarly, the relative prostate weight ratio was also elevated by TP, which was reduced following the administration of Fina, Saw, and UMB (50 or $100 \mathrm{mg} / \mathrm{kg}$ ) (Figure 5D). The prostate weight to body weight ratio (PW/BW) was measured to determine whether the effect of UMB on prostate weight was affected by body weight. $\mathrm{PW} / \mathrm{BW}$ showed a similar tendency to prostate weight, suggesting that prostate weight loss was not affected by body weight (Figure 5E). 
A

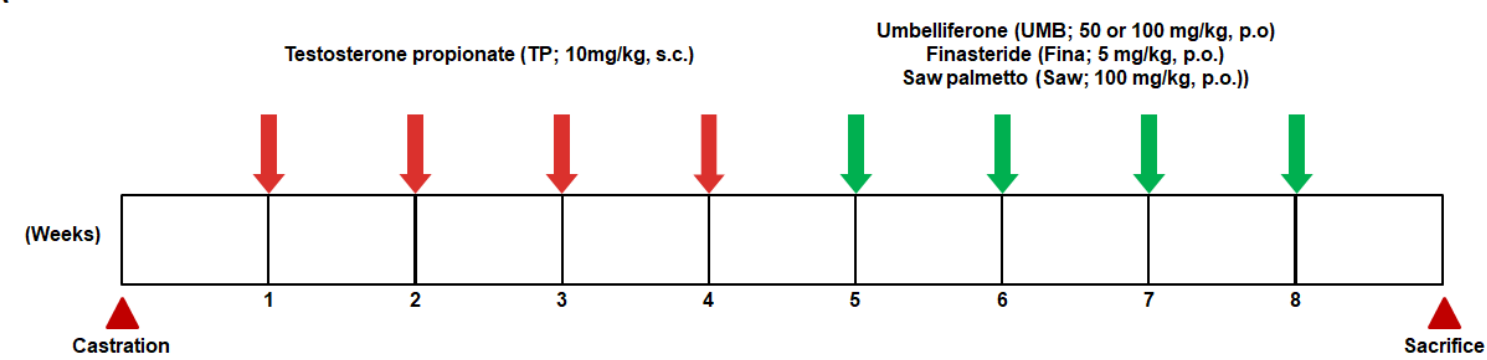

B

C

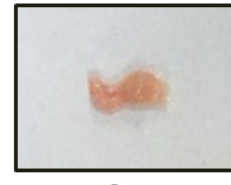

Con

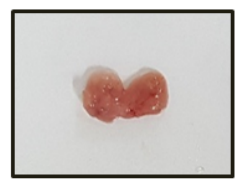

Saw

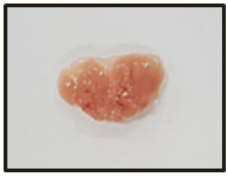

TP

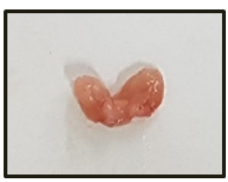

UM
50

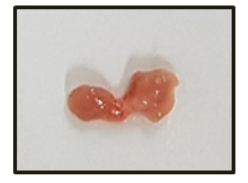

Fina

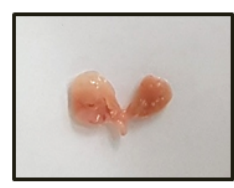

UMB
100

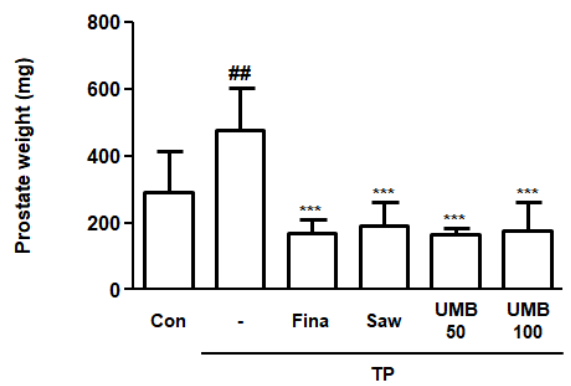

E

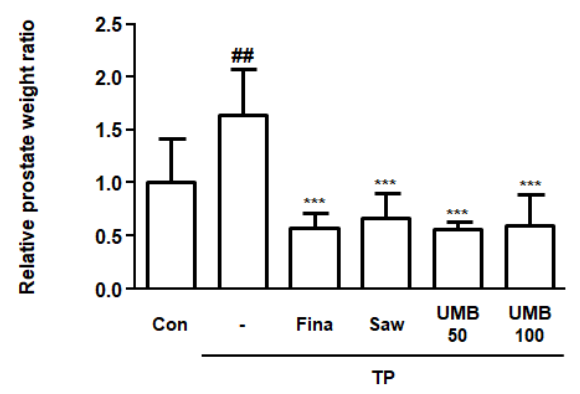

Figure 5. Effect of UMB on prostate enlargement in TP-induced rats. (A) Schematic overview of the experimental design of the in vivo study. (B) Visual comparison of the prostates of six experimental groups. (C-E) Comparative analysis of prostate weight in each group. (C) Prostate weight, (D) relative prostate weight ratio, and (E) prostate weight to body weight $(\mathrm{PW} / \mathrm{BW})$ ratio were measured. Relative prostate weight ratio was calculated by dividing the individual prostate weights of the experimental group by the mean prostate weight of the Con. The PW/BW ratio was calculated by dividing the prostate weight $(\mathrm{mg})$ by the mean body weight $(\mathrm{g})$. The data represent as mean \pm S.D. of five rats per group. \#\# $p<0.01$ vs. Con group; ${ }^{* * *} p<0.001$ vs. TP group.

\subsection{Effect of UMB on Histological Alterations in TP-Induced Rats}

To analyze the histological alterations in the prostate of TP-induced rats, hematoxylin and eosin (H\&E) staining was performed to measure the epithelial thickness. The epithelial thickness, which was increased approximately 2.62-fold following TP injection, was significantly decreased following administration of Fina, Saw, and UMB (50 or $100 \mathrm{mg} / \mathrm{kg}$ ) (Figure 6A). Furthermore, immunohistochemical analysis was performed to examine the expression of PCNA and STAT3 in relation to cell proliferation in prostate tissue. The expression of PCNA and p-STAT3 (Tyr 705) was highly detected in prostate tissue by TP injection, which was diminished by administration of Fina, Saw, and UMB (50 or $100 \mathrm{mg} / \mathrm{kg}$ ) (Figure 6B). Therefore, we confirmed that the inhibitory effect of UMB on cell proliferation was related to the inhibition of STAT3 phosphorylation in TP-induced rats. 
A

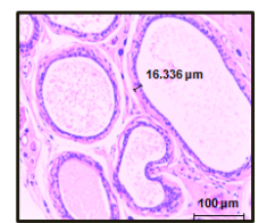

Con

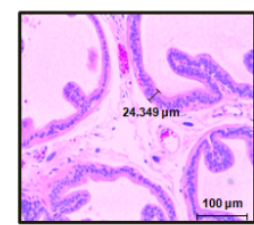

Saw

B

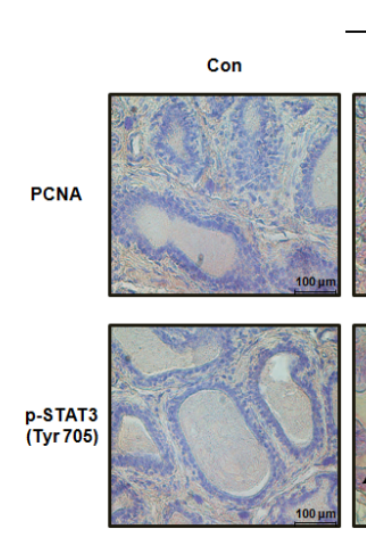

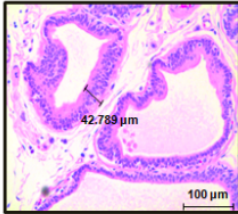

TP

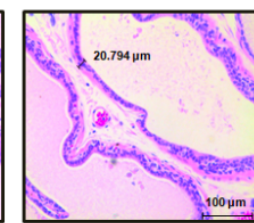

UMB
50

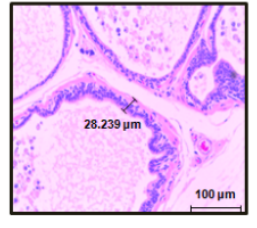

Fina

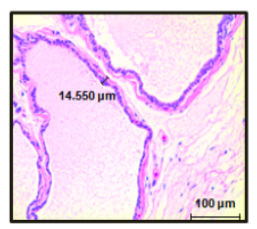

UMB
100

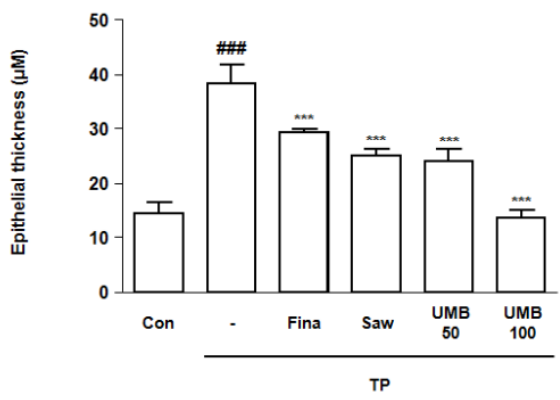

TP
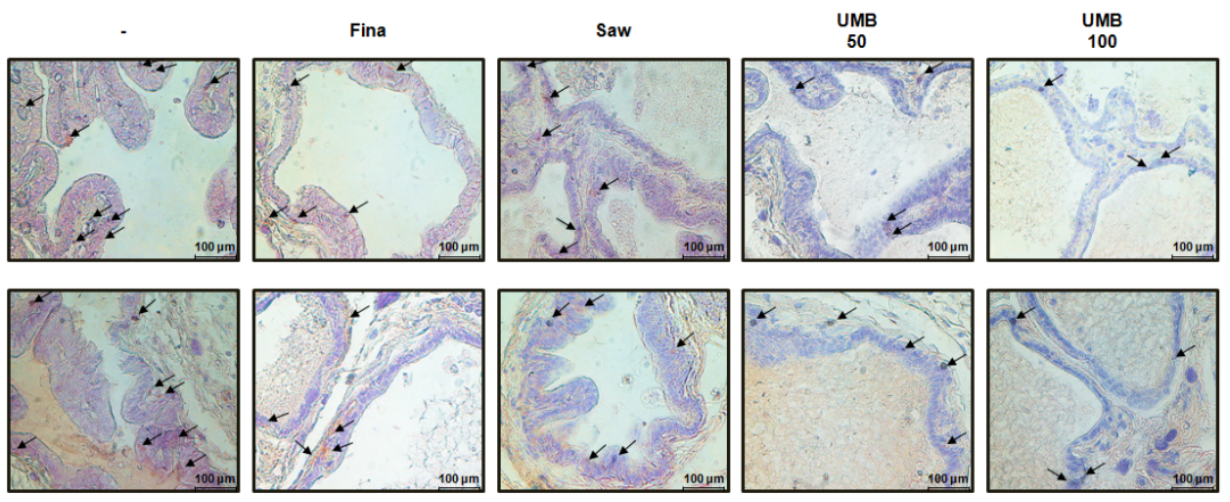

Figure 6. Effect of UMB on histological alterations in TP-induced rats. (A) Prostate tissue sections stained with hematoxylin and eosin (H\&E) were observed using a Leica microscope (original magnification $20 \times$ ). Epithelial thickness in the prostate tissues was measured and represented as the mean \pm S.D. of five rats per experimental group. The expression of (B) PCNA and p-STAT3 (Tyr 705) was detected in prostate tissue of rats by immunohistochemical analysis using a Leica microscope (original magnification $20 \times$ ). The black arrows indicate the immunoreactivity of PCNA and p-STAT3 (Tyr 705) highlighted in the prostate tissues of each group. ${ }^{\# \#} p<0.001$ vs. Con group; ${ }^{* * *} p<0.001$ vs. TP group.

\section{Discussion}

The etiology of BPH has not yet been fully elucidated, but unregulated cell proliferation represents one of the major events in BPH progression. In addition, cell proliferation is closely associated with hormone disturbances, aging, and dysregulation of several growth factors [29]. Among these factors, increased androgen levels play a key role in the onset of $\mathrm{BPH}$; therefore, treatment with 5ARI, including Fina, has been mainly used for patients with BPH [30]. However, long-term application of synthetic drugs such as Fina causes adverse effects, including impotence, loss of libido, hot flushes, fatigue, and psychological anxiety [31]. Hence, many studies are being conducted to identify synthetic drug alternatives from natural products with potential therapeutic effects and fewer side effects.

$\mathrm{UMB}$ is a naturally occurring comestible coumarin derivative of benzopyrone with a variety of biological activities. Its molecular structure is shown in Figure 1A. The presence of UMB in many medicinal plants and vegetables, along with its various pharmacological activities, emphasizes the utilization of UMB in the current study. Recently, Kandil et al. reported that 7-substituted UMB derivatives act as AR antagonists in the treatment of prostate cancer and breast cancer [32]. According to their results, the 7-substituted UMB derivative also inhibited cell proliferation in the human prostate cancer cell line, $22 \mathrm{Rv} 1$. The anti-cancer effect of UMB was further validated by Shen et al., who demonstrated that UMB treatment induces programmed cell death and cell cycle arrest in both early and late prostate cancer cells [22]. To the best of our knowledge, no previous studies 
have evaluated the effect of UMB on BPH. Thus, the present study sought to elucidate the anti-BPH effect of UMB and its underlying mechanisms in vitro and in vivo. Given that hormonal imbalance and pathological proliferation are the most prominent features of $\mathrm{BPH}$, we constructed and used a human prostate epithelial cell line, BPH-1 (immortalized with SV-40 large T-antigen), and TP-induced rats subjected to orchiectomy for the study.

To understand how UMB inhibits aberrant proliferation of BPH-1 cells, the expression of genes related to the androgen/AR signaling pathway and PCNA were analyzed following UMB treatment. PCNA, a DNA polymerase delta auxiliary protein, is specifically expressed in the cell nucleus and is a significant marker for cell proliferation, synthesized in the G1/S phase of the cell cycle [33]. The overexpression of AR, SRC-1, PSA, and PCNA in BPH-1 cells was significantly inhibited by UMB treatment, indicating that UMB inhibits androgen/AR signaling-dependent cell proliferation (Figure 1). Altintas et al. reported that E2F1 directly interacts with AR in prostate cells and regulates cell proliferation by mediating the transcription of androgen-responsive gene expression [34]. The cyclin-Cdk complex promotes the $\mathrm{pRb}$-mediated release of E2F1 in the late G1 phase, leading to the transcription of genes required for G1/S phase transition and DNA replication [35]. In contrast, p21 ${ }^{\text {Waf1/Cip1 }}$ and p27 ${ }^{\mathrm{Kip} 1}$, members of the Cip/Kip family that are expressed in the G1 phase, play an important role in controlling $\mathrm{pRb}$ by inhibiting a wide range of Cdks, including Cdk4/ 6 and Cdk2 [36]. A study by Jiménez-Orozco et al. revealed that UMB exhibits a cytostatic effect by selectively reducing the percentage of cells expressing cyclin D1, which is consistent with the inhibition of the G1/S transition in the cell cycle [37]. Strikingly, our results also indicated that UMB treatment reduced the expression of cyclin D1-Cdk4 and cyclin E-Cdk2, while increasing the expression of p21 Waf1/Cip1 and p27Kip1 (Figure 2A). Furthermore, UMB treatment prevented the dissociation of E2F1 by interfering with $\mathrm{pRb}$ (Figures $2 \mathrm{~B}$ and 3 ). Accordingly, the present study suggests that UMB inhibits abnormal cell proliferation through G1/S phase arrest of BPH-1 cells.

STAT3, which plays a critical role in the G1/S phase transition, was originally identified as a transcription factor activated by interleukin- 6 , and has subsequently been reported to transduce signals from additional cytokines, hormones, and growth factors [15]. Upstream kinases that regulate phosphorylation and transcriptional activation of STAT3, such as JAK2, JNK, and SRC, have been previously characterized as mediators of the non-canonical TGF $\beta$ signaling [38]. In this regard, the present study also demonstrated the inhibitory effect of UMB on TGF $\beta 1$ and p-STAT3 (Tyr 705) expression (Figure 4). Furthermore, to evaluate the effect of UMB in vivo, we established a rat model in which BPH was induced by pre-injecting TP subcutaneously for four weeks, followed by oral administration of UMB for the next four weeks. Administration of UMB (50 or $100 \mathrm{mg} / \mathrm{kg}$ ) decreased the prostate weight, which was significantly increased by TP, similar to the positive controls Fina and Saw (Figure 5). These results are consistent with our histological analysis of the prostate. Epithelial thickness, which was markedly increased in the prostate of rats with $\mathrm{BPH}$, was reduced following administration of Fina, Saw, and UMB (50 or $100 \mathrm{mg} / \mathrm{kg}$ ) (Figure 6A). As an increased expression of PCNA and p-STAT3 (Tyr 705) correlates with cell proliferation, we further confirmed the inhibitory effect of UMB on cell proliferation by analyzing the expression of these markers in the prostate. The increased expression of PCNA and p-STAT3 (Tyr 705) in the prostate of rats with BPH was significantly decreased by administration of Fina, Saw, and UMB (50 or $100 \mathrm{mg} / \mathrm{kg}$ ) (Figure 6B). Taken together, the present study demonstrated that the anti-BPH effect of UMB was mediated through inhibition of cell proliferation and G1/S phase cell cycle progression, both in vitro and in vivo.

\section{Materials and Methods}

\subsection{Chemicals and Reagents}

Fetal bovine serum (FBS) was obtained from Life Technologies Inc. (Grand Island, NY, USA). Penicillin-streptomycin solution was obtained from GE Healthcare Life Sciences Inc. (Chicago, IL, USA). Primary antibodies against PCNA (Cat. no. sc-56), AR (Cat. no. 
sc-816), SRC-1 (Cat. no. sc-32789), cyclin D1 (Cat. no. sc-753), Cdk4 (Cat. no. sc-23896), cyclin E (Cat. no. sc-481), Cdk2 (Cat. no. sc-748), p21 Waf1/Cip1 (Cat. no. sc-397), p27Kip1 (Cat. no. sc-528), pRb (Cat. no. sc-377528), E2F1 (Cat. no. sc-193), TGF $\beta 1$ (Cat. no. sc-146), and $\beta$-actin (Cat. no. sc-47778) were obtained from Santa Cruz Biotechnology, Inc. (Dallas, TX, USA). Primary antibody against PSA (Cat. no. PB9259) was obtained from Boster Biological Technology (Pleasanton, CA, USA). Primary antibody against p-STAT3 (Tyr 705) (Cat. no. 9145) was obtained from Cell Signaling Technology (Danvers, MA, USA). Horseradish peroxidase-conjugated secondary antibodies were obtained from Jackson ImmunoResearch Laboratories, Inc. (West Grove, PA, USA). Oligonucleotide primers for PCNA, AR, SRC-1, PSA, cyclin D1, Cdk4, cyclin E, Cdk2, p27 Kip1 , Rb, E2F1, TGF $\beta 1$, and $\beta$-actin were purchased from Bioneer (Daejeon, Republic of Korea). Power SYBR ${ }^{\circledR}$ green PCR master mix was obtained from Applied Biosystems (Foster City, CA, USA). Alexa Fluor 488 goat anti-rabbit IgG $(\mathrm{H}+\mathrm{L})$ was obtained from Invitrogen (Carlsbad, CA, USA). Testosterone propionate (TP) was procured from Wako Pure Chemicals Industries, Ltd. (Tokyo, Japan). Fina was obtained from Merck \& Co., Inc. (Whitehouse Station, NJ, USA). Saw was purchased from Chong Kun Dang Healthcare Corp. (Seoul, Republic of Korea). All other reagents were acquired from Sigma-Aldrich (St. Louis, MO, USA).

\subsection{Preparation of $U M B$ and Cell Culture}

UMB (Cat. no. H24003, purity 99\%) was purchased from Sigma Chemical Co. (St. Louis, MO, USA) and dissolved in DMSO for the experiments. The stock solutions were stored at $-20^{\circ} \mathrm{C}$. Human BPH-1 cells, representing epithelial cell types, were obtained from the Leibniz Institute DSMZ (Braunschweig, Lower Saxony, Germany). BPH-1 cells were maintained in RPMI 1640 medium (Gibco, Waltham, MA, USA) containing 20\% FBS (Life Technologies Inc.) and $100 \mathrm{mg} / \mathrm{mL}$ penicillin-streptomycin (GE Healthcare Life Sciences Inc., Chicago, IL, USA) at $37^{\circ} \mathrm{C}$ in a $5 \% \mathrm{CO}_{2}$ incubator.

\subsection{Cell Viability Assays}

BPH-1 cells were plated in a 96-well plate at a concentration of $1 \times 10^{5}$ cells/well and cultured overnight. The cells were treated with 6.25-400 $\mu \mathrm{M} \mathrm{UMB}$ for $24 \mathrm{~h}$. Then, the cells were incubated with MTT solution $(5 \mathrm{mg} / \mathrm{mL})$ for $4 \mathrm{~h}$ at $37^{\circ} \mathrm{C}$. The supernatant was aspirated, and the insoluble formazan crystals were dissolved in DMSO. The absorbance was measured at $540 \mathrm{~nm}$ using a BioTek Epoch microplate spectrophotometer (Winooski, VT, USA).

\subsection{Western Blot Analysis}

BPH-1 cells were homogenized in PRO-PREPTM protein extraction solution (Cat. no. 17081, iNtRON Biotechnology, Gyeonggi-do, Korea), and cell debris was removed by micro-centrifugation at $15,920 \times g$, followed by quick freezing of the supernatants. Protein concentration was determined using the Bio-Rad protein assay reagent according to the manufacturer's instructions (Bio-Rad, Hercules, CA, USA). Proteins were separated on a sodium dodecyl sulfate polyacrylamide gel and electroblotted onto a polyvinylidene fluoride membrane. The immunoreactive bands were detected by enhanced chemiluminescence (GE Healthcare Life Sciences Inc., Chicago, IL, USA), as described previously [39].

\subsection{Isolation of Total RNA and Reverse Transcription Quantitative Polymerase Chain Reaction (RT-qPCR)}

Total RNA was isolated from BPH-1 cells using an Easy-Blue RNA extraction kit (iNtRON Biotechnology, Inc., Gyeonggi, Korea), according to the manufacturer's instructions. Total RNA samples were quantified using an Epoch ${ }^{\circledR}$ microvolume spectrophotometer system (BioTek Instruments, Inc., Winooski, VT, USA). cDNA was obtained by reverse transcription using total RNA $(1 \mu \mathrm{g}), \mathrm{d}(\mathrm{T}) 16$ primer, and avian myeloblastosis virus reverse transcriptase (AMV-RT). Relative gene expression was measured using a Real-Time PCR System 7500 (Applied Biosystems, Foster City, CA, USA) with Power SYBR ${ }^{\circledR}$ green PCR master mix. The primer sequences are listed in Table 1. 
Table 1. Primer sequences.

\begin{tabular}{ccc}
\hline Gene & Forward Primer $\left(\mathbf{5}^{\prime} \mathbf{- 3}^{\prime} \mathbf{)}\right.$ & Reverse Primer $\mathbf{( 5}^{\prime} \mathbf{- 3}^{\prime} \mathbf{)}$ \\
\hline PCNA & TTAAACGGTTGCAGGCGTAG & AGGAAAGTCTAGCTGGTTTCGG \\
AR & GAGCCAGGTGTAGTGTGTGC & TCGTCCACGTGTAAGTTGCG \\
SRC-1 & GCTGGTATCCTTCCTTAGTG & TGGCGTTGCTTGTTGTGGTG \\
PSA & ATAGGATTGCCCAGGCAGAA & CTAAGGGTAAAAGCAGGGAGAGAGT \\
Cyclin D1 & ACGGCCGAGAAGCTGTGCATC & CCTCCGCCTCTGGCATTTTGGAG \\
Cdk4 & ATGGCTACCTCTCGATATGAGC & CATTGGGGACTCTCACACTCT \\
Cyclin E & GACGGGGAGCTCAAAACTGA & TACAACGGAGCCCAGAACAC \\
Cdk2 & TTCTATGCCTGATTACAAGCC & CTGGCTTGGTCACATCCT \\
p27Kip1 & AACGTGCGAGTGTCTAACGG & CCCTCTAGGGGTTTGTGATTCT \\
Rb & ATGGTTCACCTCGAACACCC & TTTCGACACAACCCTGTCCC \\
E2F1 & AAGAACCGCTGTTGTCCCG & TCGAGGCCGAAGTGGTAGTC \\
TGF 1 & CTATCGACATGGAGCTGGTGAAG & CGTGGAGCTGAAGCAATAGTTGG \\
$\beta$-actin & GGCCAGGTCATCACCATTGG & CTTTGCGGATGTCCACGTCA \\
\hline
\end{tabular}

\subsection{Immunofluorescence Staining}

BPH-1 cells $\left(1 \times 10^{5}\right.$ cells $\left./ \mathrm{mL}\right)$ were cultured in a chamber slide (Lab-Tek II chamber slide \#154526) for $24 \mathrm{~h}$ to detect E2F1. After treatment with UMB, the cells were fixed with $100 \%$ methanol for $30 \mathrm{~min}$ at room temperature and blocked with $10 \%$ normal goat serum (Gibco, Grand Island, NY, USA). The cells were incubated overnight with specific primary antibodies in a $10 \%$ blocking solution at $4{ }^{\circ} \mathrm{C}$. After washing the primary antibodies with $0.3 \%$ Triton $X$ in PBS, the cells were incubated with Alexa Fluor 488 goat anti-rabbit $\operatorname{IgG}(\mathrm{H}+\mathrm{L})$ for $1 \mathrm{~h}$. The nuclei were counterstained with 4', 6-diamidino-2-phenylindole (DAPI, Life Technologies, Carlsbad, CA, USA) and observed under an optical microscope (ECLIPSE Ni-U, Nikon, Tokyo, Japan).

\subsection{Animals}

Eight-week-old male Wistar rats (200 $\pm 20 \mathrm{~g})$ were obtained from Daehan Biolink Co. Ltd. (Daejeon, Korea) and maintained under steady conditions (light cycle: 12 h; temperature: $20-25{ }^{\circ} \mathrm{C}$; humidity: 40-60\%) with access to standard laboratory diet and tap water ad libitum. All procedures were conducted in accordance with the guidelines of the Institutional Animal Care and Use Committee of the Sangji University (approval number \#2019-16). The rats were castrated to rule out the effect of intrinsic testosterone in all rats, except the sham-operated control group (Con) [40]. After a recovery period, $\mathrm{BPH}$ was induced by subcutaneous injections (s.c.) of TP $(10 \mathrm{mg} / \mathrm{kg} /$ day $)$ to the castrated rats, excluding Con, for four weeks. Rats with BPH were assigned to five groups $(n=5)$ and orally administered water (BPH), Fina (5 mg/kg, Fina), Saw (100 mg/kg, Saw), and UMB (50 or $100 \mathrm{mg} / \mathrm{kg}$ ) for four weeks excluding the weekends.

\subsection{Hematoxylin and Eosin (HEE) Staining and Immunohistochemistry (IHC)}

Prostate tissues from the rats were fixed in $10 \%$ buffered formalin and embedded in paraffin. The tissue blocks were cut into $8 \mu \mathrm{m}$ thickness and stained with H\&E prior to histological evaluation. Images of the epithelial thickness were acquired using the Leica Application Suite software (LAS version 3.3.0, Leica Microsystems, Inc., Wetzlar, Germany). The tissue sections were placed onto microscopy slides (Muto Pure Chemicals Co., LTD., Tokyo, Japan), deparaffinized, and the endogenous peroxidase activity was depleted. The sections were then blocked with normal goat serum and incubated overnight at $4{ }^{\circ} \mathrm{C}$ with a primary antibody (1:200). The slides were then incubated with corresponding horseradish peroxidase-conjugated secondary antibody (1:500) and incubated at room temperature for $2 \mathrm{~h}$. After washing thrice in PBS, the sections were incubated with 3,3'-diaminobenzidine (DAB) solution (Abcam, Cambridge, MA, USA). Finally, the tissues were counterstained with hematoxylin and mounted with mounting medium (Agilent Technologies, Inc., Santa Clara, CA, USA). Images were acquired using NIS-Elements F (version 4.0., Nikon, Tokyo, Japan). 


\subsection{Statistical Analysis}

Data are expressed as the mean \pm standard deviation (S.D.) of triplicate experiments. Significance was determined using Dunnett's post hoc test for ANOVA using GraphPad Prism software (version 5.01, San Diego, CA, USA). Statistical significance was set at $p<0.05$.

\section{Conclusions}

Our findings highlight the inhibitory effect of UMB on cell proliferation of BPH1 cells and TP-induced rats. These effects appear to be mediated by blockade of the androgen/AR signaling pathway as well as G1/S phase cell cycle arrest through regulation of the E2F1/STAT3 axis. Moreover, UMB administration reduced the enlargement of the prostate in TP-induced rats, which was slightly superior to that observed with the conventional drugs, Fina and Saw. Thus, our findings suggest that UMB may be a potential therapeutic agent for the treatment of $\mathrm{BPH}$.

Author Contributions: Conceptualization, H.-J.K., B.-R.J. and H.-J.A.; Data curation, H.-J.K., B.-R.J. and H.-J.A.; Formal analysis, H.-J.K. and H.-J.A.; Funding acquisition, H.-J.A.; Investigation, H.-J.K. and H.-J.A.; Methodology, H.-J.K.; Supervision, H.-J.A.; Visualization, H.-J.K.; Writing-original draft, H.-J.K.; Writing-review and editing, H.-J.K., B.-R.J. and H.-J.A. All authors have read and agreed to the published version of the manuscript.

Funding: This research was supported by the Basic Science Research Program through the National Research Foundation of Korea (NRF), funded by the Ministry of Science, ICT \& Future Planning (NRF2019R1A2C4070234), and the Research Fund from Sangji University in 2020.

Institutional Review Board Statement: The study was conducted according to the guidelines of the Declaration of Helsinki, and approved by the Institutional Animal Care and Use Committee (IACUC) of Sangii University (protocol code No. 2019-16; approved on 2 December 2019).

Informed Consent Statement: Not applicable.

Data Availability Statement: Not applicable.

Conflicts of Interest: The authors declare no conflict of interest.

$\begin{array}{ll}\text { Abbreviations } \\ \text { AR } & \text { Androgen receptor } \\ \text { BPH } & \text { Benign prostatic hyperplasia } \\ \text { DHT } & \text { Dihydrotestosterone } \\ \text { E2F1 } & \text { E2F transcription factor } 1 \\ \text { Fina } & \text { Finasteride } \\ \text { PCNA } & \text { Proliferating cell nuclear antigen } \\ \text { PSA } & \text { Prostate-specific antigen } \\ \text { Saw } & \text { Saw palmetto } \\ \text { STAT3 } & \text { Signal transducer and activator of transcription } 3 \\ \text { TP } & \text { Testosterone propionate } \\ \text { TGF } \beta 1 & \text { Transforming growth factor beta } 1 \\ \text { UMB } & \text { Umbelliferone }\end{array}$

\section{References}

1. Youn, D.H.; Park, J.; Kim, H.L.; Jung, Y.; Kang, J.; Jeong, M.Y.; Sethi, G.; Seok Ahn, K.; Um, J.Y. Chrysophanic acid reduces testosterone-induced benign prostatic hyperplasia in rats by suppressing 5alpha-reductase and extracellular signal-regulated kinase. Oncotarget 2017, 8, 9500-9512. [CrossRef]

2. Zhang, L.; Fan, X.R.; Xie, H.; He, Q.H.; Nie, Y.S.; Zhang, M.; Yan, M. Anti-Inflammatory and Antioxidant Effects of Kelong-Capsule on Testosterone-Induced Benign Prostatic Hyperplasia in Rats. Evid. Based Complement. Altern. Med. eCAM 2018, $2018,5290514$. [CrossRef] 
3. Sheng, J.; Yang, Y.; Cui, Y.; He, S.; Wang, L.; Liu, L.; He, Q.; Lv, T.; Han, W.; Yu, W.; et al. M2 macrophage-mediated interleukin4 signalling induces myofibroblast phenotype during the progression of benign prostatic hyperplasia. Cell Death Dis. $2018,9,755$. [CrossRef] [PubMed]

4. Lee, G.; Shin, J.; Choi, H.; Jo, A.; Pan, S.; Bae, D.; Lee, Y.; Choi, C. Cynanchum wilfordii Ameliorates Testosterone-Induced Benign Prostatic Hyperplasia by Regulating 5alpha-Reductase and Androgen Receptor Activities in a Rat Model. Nutrients 2017, 9, 1070. [CrossRef] [PubMed]

5. Shin, Y.S.; Karna, K.K.; Choi, B.R.; Park, J.K. Finasteride and Erectile Dysfunction in Patients with Benign Prostatic Hyperplasia or Male Androgenetic Alopecia. World J. Men's Health 2019, 37, 157-165. [CrossRef] [PubMed]

6. Kaplan, S.A.; Chung, D.E.; Lee, R.K.; Scofield, S.; Te, A.E. A 5-year retrospective analysis of 5alpha-reductase inhibitors in men with benign prostatic hyperplasia: Finasteride has comparable urinary symptom efficacy and prostate volume reduction, but less sexual side effects and breast complications than dutasteride. Int. J. Clin. Pract. 2012, 66, 1052-1055. [PubMed]

7. D'Amico, R.; Genovese, T.; Cordaro, M.; Siracusa, R.; Gugliandolo, E.; Peritore, A.F.; Interdonato, L.; Crupi, R.; Cuzzocrea, S.; Di Paola, R.; et al. Palmitoylethanolamide/Baicalein Regulates the Androgen Receptor Signaling and NF-kappaB/Nrf2 Pathways in Benign Prostatic Hyperplasia. Antioxidants 2021, 10, 1014. [CrossRef]

8. Kwon, Y. Use of saw palmetto (Serenoa repens) extract for benign prostatic hyperplasia. Food Sci. Biotechnol. 2019, 28, 1599-1606. [CrossRef]

9. Pais, P. Potency of a novel saw palmetto ethanol extract, SPET-085, for inhibition of 5alpha-reductase II. Adv. Ther. 2010, 27, 555-563. [CrossRef]

10. Powell, S.M.; Christiaens, V.; Voulgaraki, D.; Waxman, J.; Claessens, F.; Bevan, C.L. Mechanisms of androgen receptor signalling via steroid receptor coactivator-1 in prostate. Endocr. Relat. Cancer 2004, 11, 117-130. [CrossRef]

11. Ye, X.; Han, S.J.; Tsai, S.Y.; DeMayo, F.J.; Xu, J.; Tsai, M.J.; O’Malley, B.W. Roles of steroid receptor coactivator (SRC)-1 and transcriptional intermediary factor (TIF) 2 in androgen receptor activity in mice. Proc. Natl. Acad. Sci. USA 2005, 102, 9487-9492. [CrossRef]

12. Zheng, H.; Xu, W.; Lin, J.; Peng, J.; Hong, Z. Qianliening capsule treats benign prostatic hyperplasia via induction of prostatic cell apoptosis. Mol. Med. Rep. 2013, 7, 848-854. [CrossRef]

13. Robles, L.D.; Frost, A.R.; Davila, M.; Hutson, A.D.; Grizzle, W.E.; Chakrabarti, R. Down-regulation of Cdc6, a cell cycle regulatory gene, in prostate cancer. J. Biol. Chem. 2002, 277, 25431-25438. [CrossRef]

14. Singh, S.K.; Banerjee, S.; Acosta, E.P.; Lillard, J.W.; Singh, R. Resveratrol induces cell cycle arrest and apoptosis with docetaxel in prostate cancer cells via a p53/ p21WAF1/CIP1 and p27KIP1 pathway. Oncotarget 2017, 8, 17216-17228. [CrossRef]

15. Guadagnin, E.; Narola, J.; Bonnemann, C.G.; Chen, Y.W. Tyrosine 705 Phosphorylation of STAT3 Is Associated with Phenotype Severity in TGFbeta1 Transgenic Mice. Biomed Res. Int. 2015, 2015, 843743. [CrossRef]

16. Sherry, M.M.; Reeves, A.; Wu, J.K.; Cochran, B.H. STAT3 is required for proliferation and maintenance of multipotency in glioblastoma stem cells. Stem Cells 2009, 27, 2383-2392. [CrossRef] [PubMed]

17. Rezaee, R.; Behravan, E.; Behravan, J.; Soltani, F.; Naderi, Y.; Emami, B.; Iranshahi, M. Antigenotoxic activities of the natural dietary coumarins umbelliferone, herniarin and 7-isopentenyloxy coumarin on human lymphocytes exposed to oxidative stress. Drug Chem. Toxicol. 2014, 37, 144-148. [CrossRef] [PubMed]

18. Wu, W.F.; Wang, J.N.; Li, Z.; Wei, B.; Jin, J.; Gao, L.; Li, H.D.; Li, J.; Chen, H.Y.; Meng, X.M. 7-Hydroxycoumarin protects against cisplatin-induced acute kidney injury by inhibiting necroptosis and promoting Sox9-mediated tubular epithelial cell proliferation. Phytomedicine Int. J. Phytother. Phytopharm. 2020, 69, 153202. [CrossRef] [PubMed]

19. Vijayalakshmi, A.; Sindhu, G. Umbelliferone arrest cell cycle at G0/G1 phase and induces apoptosis in human oral carcinoma (KB) cells possibly via oxidative DNA damage. Biomed. Pharmacother. Biomed. Pharmacother. 2017, 92, 661-671. [CrossRef]

20. Germoush, M.O.; Othman, S.I.; Al-Qaraawi, M.A.; Al-Harbi, H.M.; Hussein, O.E.; Al-Basher, G.; Alotaibi, M.F.; Elgebaly, H.A.; Sandhu, M.A.; Allam, A.A.; et al. Umbelliferone prevents oxidative stress, inflammation and hematological alterations, and modulates glutamate-nitric oxide-cGMP signaling in hyperammonemic rats. Biomed. Pharmacother. Biomed. Pharmacother. 2018, 102, 392-402. [CrossRef] [PubMed]

21. Lopez-Gonzalez, J.S.; Prado-Garcia, H.; Aguilar-Cazares, D.; Molina-Guarneros, J.A.; Morales-Fuentes, J.; Mandoki, J.J. Apoptosis and cell cycle disturbances induced by coumarin and 7-hydroxycoumarin on human lung carcinoma cell lines. Lung Cancer 2004, 43, 275-283. [CrossRef]

22. Shen, J.Q.; Zhang, Z.X.; Shen, C.F.; Liao, J.Z. Anticarcinogenic effect of Umbelliferone in human prostate carcinoma: An in vitro study. J. B.U. Off. J. Balk. Union Oncol. 2017, 22, 94-101.

23. Liu, J.; Fang, T.; Li, M.; Song, Y.; Li, J.; Xue, Z.; Li, J.; Bu, D.; Liu, W.; Zeng, Q.; et al. Pao Pereira Extract Attenuates TestosteroneInduced Benign Prostatic Hyperplasia in Rats by inhibiting 5alpha-Reductase. Sci. Rep. 2019, 9, 19703. [CrossRef]

24. Song, J.H.; Hwang, B.; Chung, H.J.; Moon, B.; Kim, J.W.; Ko, K.; Kim, B.W.; Kim, W.R.; Kim, W.J.; Myung, S.C.; et al. Peanut Sprout Extracts Cultivated with Fermented Sawdust Medium Inhibits Benign Prostatic Hyperplasia In Vitro and In Vivo. World J. Men's Health 2020, 38, 385-396. [CrossRef]

25. Zhao, X.; Harashima, H.; Dissmeyer, N.; Pusch, S.; Weimer, A.K.; Bramsiepe, J.; Bouyer, D.; Rademacher, S.; Nowack, M.K.; Novak, B.; et al. A general G1/S-phase cell-cycle control module in the flowering plant Arabidopsis thaliana. PLoS Genet. 2012, 8, e1002847. [CrossRef] [PubMed] 
26. Sheldon, L.A. Inhibition of E2F1 activity and cell cycle progression by arsenic via retinoblastoma protein. Cell Cycle 2017, 16, 2058-2072. [CrossRef] [PubMed]

27. Yang, C.; Su, H.; Liao, X.; Han, C.; Yu, T.; Zhu, G.; Wang, X.; Winkler, C.A.; O’Brien, S.J.; Peng, T. Marker of proliferation $\mathrm{Ki}-67$ expression is associated with transforming growth factor beta 1 and can predict the prognosis of patients with hepatic $\mathrm{B}$ virus-related hepatocellular carcinoma. Cancer Manag. Res. 2018, 10, 679-696. [CrossRef] [PubMed]

28. Caldera, V.; Mellai, M.; Annovazzi, L.; Valente, G.; Tessitore, L.; Schiffer, D. Stat3 expression and its correlation with proliferation and apoptosis/autophagy in gliomas. J. Oncol. 2008, 2008, 219241. [CrossRef]

29. Roehrborn, C.G. Pathology of benign prostatic hyperplasia. Int. J. Impot. Res. 2008, 20 (Suppl. 3), S11-S18. [CrossRef]

30. Tao, R.; Miao, L.; Yu, X.; Orgah, J.O.; Barnabas, O.; Chang, Y.; Liu, E.; Fan, G.; Gao, X. Cynomorium songaricum Rupr demonstrates phytoestrogenic or phytoandrogenic like activities that attenuates benign prostatic hyperplasia via regulating steroid 5-alpha-reductase. J. Ethnopharmacol. 2019, 235, 65-74. [CrossRef]

31. Tombal, B. A holistic approach to androgen deprivation therapy: Treating the cancer without hurting the patient. Urol. Int. 2009, 83, 373-378. [CrossRef] [PubMed]

32. Kandil, S.; Westwell, A.D.; McGuigan, C. 7-Substituted umbelliferone derivatives as androgen receptor antagonists for the potential treatment of prostate and breast cancer. Bioorg. Med. Chem. Lett. 2016, 26, 2000-2004. [CrossRef]

33. Park, H.S.; Seo, C.S.; Wijerathne, C.U.; Jeong, H.Y.; Moon, O.S.; Seo, Y.W.; Won, Y.S.; Son, H.Y.; Lim, J.H.; Kwun, H.J. Effect of Veratrum maackii on Testosterone Propionate-Induced Benign Prostatic Hyperplasia in Rats. Biol. Pharm. Bull. 2019, 42, 1-9. [CrossRef]

34. Altintas, D.M.; Shukla, M.S.; Goutte-Gattat, D.; Angelov, D.; Rouault, J.P.; Dimitrov, S.; Samarut, J. Direct cooperation between androgen receptor and E2F1 reveals a common regulation mechanism for androgen-responsive genes in prostate cells. Mol. Endocrinol. 2012, 26, 1531-1541. [CrossRef]

35. Glorian, V.; Allegre, J.; Berthelet, J.; Dumetier, B.; Boutanquoi, P.M.; Droin, N.; Kayaci, C.; Cartier, J.; Gemble, S.; Marcion, G.; et al. DNA damage and S phase-dependent E2F1 stabilization requires the cIAP1 E3-ubiquitin ligase and is associated with K63-poly-ubiquitination on lysine 161/164 residues. Cell Death Dis. 2017, 8, e2816. [CrossRef]

36. Wei, M.; Liu, B.; Gu, Q.; Su, L.; Yu, Y.; Zhu, Z. Stat6 cooperates with Sp1 in controlling breast cancer cell proliferation by modulating the expression of p21(Cip1/WAF1) and p27 (Kip1). Cell. Oncol. 2013, 36, 79-93. [CrossRef]

37. Jimenez-Orozco, F.A.; Lopez-Gonzalez, J.S.; Nieto-Rodriguez, A.; Velasco-Velazquez, M.A.; Molina-Guarneros, J.A.; MendozaPatino, N.; Garcia-Mondragon, M.J.; Elizalde-Galvan, P.; Leon-Cedeno, F.; Mandoki, J.J. Decrease of cyclin D1 in the human lung adenocarcinoma cell line A-427 by 7-hydroxycoumarin. Lung Cancer 2001, 34, 185-194. [CrossRef]

38. Chakraborty, D.; Sumova, B.; Mallano, T.; Chen, C.W.; Distler, A.; Bergmann, C.; Ludolph, I.; Horch, R.E.; Gelse, K.; Ramming, A.; et al. Activation of STAT3 integrates common profibrotic pathways to promote fibroblast activation and tissue fibrosis. Nat. Commun. 2017, 8, 1130. [CrossRef] [PubMed]

39. Kim, H.J.; Jin, B.R.; An, H.J. Psoralea corylifolia L. extract ameliorates benign prostatic hyperplasia by regulating prostate cell proliferation and apoptosis. J. Ethnopharmacol. 2021, 273, 113844. [CrossRef]

40. Jin, B.R.; Cheon, S.Y.; Kim, H.J.; Kim, M.S.; Lee, K.H.; An, H.J. Anti-Proliferative Effects of Standardized Cornus officinalis on Benign Prostatic Epithelial Cells via the PCNA/E2F1-Dependent Cell Cycle Pathway. Int. J. Mol. Sci. 2020, 21, 9567. [CrossRef] [PubMed] 